\title{
Cardioscopic Detection of Left Ventricular Thrombi - With Special Reference to a Comparison With Left Ventriculography and Echocardiography -
}

\author{
Yasuto Uchida, MD; Yasumi Uchida, MD; Takeshi Sakurai, MD; \\ Masahito Kanai, MD; Seiichiro Shirai, MD; Osamu Nakagawa, MD
}

\begin{abstract}
Background: Thrombosis occurs in the left ventricle and causes ischemic cerebral attacks. However, differences in the incidence of left ventricular thrombi (LVT) among various categories of heart diseases are not known.

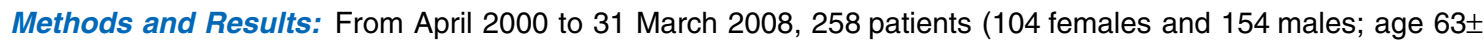
6 years) with a heart disease underwent cardioscopy of the left ventricle. LVT were detected by cardioscopy in 78 of 258 patients; $12.5 \%$ of 57 patients with stable angina, $0 \%$ of 9 with unstable angina, $45.2 \%$ of 42 with acute myocardial infarction, $23.2 \%$ of 43 with old myocardial infarction, $61.9 \%$ of 21 with idiopathic acute myocarditis, $44.3 \%$ of 68 with idiopathic chronic myocarditis, 33.3\% of 6 with rheumatic valvular disease, $25.7 \%$ of 31 with idiopathic dilated cardiomyopathy and in $8.0 \%$ of 12 with idiopathic hypertrophic cardiomyopathy. Nine of 78 thrombi were globular and 69 were mural. The detection rate of LVT by cardioscopy, left venticulography, non-contrast and contrast echocardiography was $30.2 \%, 2.7 \%, 1.9 \%$ and $7.0 \%$, respectively.
\end{abstract}

Conclusions: LVT were frequently detected by cardioscopy in patients with heart diseases. Although invasive, cardioscopy was more sensitive in detecting LVT than left ventriculography, and non-contrast and contrast echocardiography. (Circ J 2011; 75: 1920-1926)

Key Words: Cardioscopy; Contrast echocardiography; Left ventricular thrombi; Non-contrast echocardiography; Ventriculography

$\mathbf{I}$ $t$ is well known that a fibrillating left atrium is the site of thrombus formation and acts as a major supply source of thromboemboli in cerebral ischemic attacks. ${ }^{1-4}$ It is also known that the left ventricle is the site of thrombus formation in a post-infarction state. ${ }^{5}$ There have been many case reports on left ventricular thrombi (LVT) in other categories of heart disease such as peripartal cardiomyopathy, ${ }^{6}$ idiopathic dilated cardiomyopathy (DCM), ${ }^{7}$ acute myocarditis (AM),${ }^{8}$ and antiphospholipid syndrome, ${ }^{9}$ and they cause cerebral embolism. ${ }^{10,11}$ However, the exact incidence of LVT in various categories of heart disease is not well known due to the lack of systematic surveys.

Non-contrast echocardiography (UCG), ${ }^{5}$ contrast UCG $, 5,12$ computed tomography, ${ }^{13}$ magnetic resonance imaging,,${ }^{5,12}$ and left ventriculography have been used for the detection of LVT in left atrial thrombi or pulmonary thromboemboli. ${ }^{14,15}$ Although large globular thrombi can be detected, small-sized mural thrombi are difficult to detect using these imaging modalities. Furthermore, because the shadows of the targets are imaged, definite determination of thrombi is beyond these imaging modalities. Therefore, thrombus characteristics, namely whether the thrombi are fresh or organized, or red blood cell-rich or platelet-rich, which might influence the selection of the therapeutic modality, are difficult to determine with these imaging modalities.

Cardioscopy, specially fiberoptic angioscopy of the heart, is a high resolution imaging modality that enables macroscopic pathological diagnosis of heart diseases. This technique was applied for observation of the cardiac chambers and valves and abnormal intracardiac structures, including LVT. ${ }^{16-19}$

In the present study, percutaneous cardioscopy was performed to examine the incidence of LVT in patients with various types of heart diseases, and to compare the detection sensitivities among cardioscopy, left ventriculography, noncontrast UCG, and contrast UCG.

Received March 2, 2011; revised manuscript received March 22, 2011; accepted April 5, 2011; released online June 21, 2011 Time for primary review: 19 days

Department of Cardiology, Toho University Medical Center Ohmori Hospital, Tokyo (Yasuto U.); Japan Foundation for Cardiovascular Research, Funabashi (Yasumi U.); Department of Cardiology, Toho University Medical Center Sakura Hospital, Sakura (Yasumi U., T.S., M.K.); and Department of Cardiology, Funabashi-Futawa Hospital, Funabashi (S.S., O.N.), Japan

Mailing address: Yasumi Uchida, MD, Japan Foundation for Cardiovascular Research, 2-30-17 Narashinodai, Funabashi 274-0063, Japan. E-mail: uchiy@ta2.so-net.ne.jp

ISSN-1346-9843 doi:10.1253/circj.CJ-11-0248

All rights are reserved to the Japanese Circulation Society. For permissions, please e-mail: cj@j-circ.or.jp 


\begin{tabular}{|c|c|c|c|c|c|c|}
\hline \multirow{2}{*}{ Heart diseases } & \multirow{2}{*}{$\mathbf{n}$} & \multirow{2}{*}{$\begin{array}{c}\text { Gender } \\
\text { (F/M) }\end{array}$} & \multirow{2}{*}{$\begin{array}{c}\text { Age } \\
\text { (years) }\end{array}$} & \multirow{2}{*}{$\begin{array}{c}\text { Time from } \\
\text { onset }^{\#}\end{array}$} & \multicolumn{2}{|c|}{ LVG } \\
\hline & & & & & EDVI $\left(\mathrm{ml} / \mathrm{m}^{2}\right)$ & $E F$ \\
\hline SA & 56 & $18 / 38$ & $62 \pm 7$ & $4.7 \pm 2.3 \mathrm{~m}$ & $76 \pm 5$ & $64 \pm 9$ \\
\hline UA & 9 & $3 / 6$ & $64 \pm 3$ & $1.3 \pm 0.5 \mathrm{~d}$ & $85 \pm 10$ & $53 \pm 11$ \\
\hline AMI & 42 & $14 / 28$ & $63 \pm 5$ & $1.6 \pm 0.8 \mathrm{~d}$ & $78 \pm 8$ & $50 \pm 8$ \\
\hline OMI & 43 & $21 / 22$ & $63 \pm 6$ & $8.2 \pm 7.8 \mathrm{~m}$ & $81 \pm 11$ & $54 \pm 7$ \\
\hline AM & 21 & $13 / 8$ & $48 \pm 9$ & $5.2 \pm 3 d$ & $78 \pm 9$ & $47 \pm 9$ \\
\hline $\mathrm{CM}$ & 38 & $26 / 12$ & $52 \pm 9$ & $4.1 \pm 3 \mathrm{~m}$ & $91 \pm 15$ & $51 \pm 10$ \\
\hline RVD & 8 & $4 / 2$ & $42 \pm 4$ & $16.9 \pm 8 \mathrm{~m}$ & $88 \pm 12$ & $56 \pm 6$ \\
\hline $\mathrm{DCM}$ & 31 & $14 / 17$ & $46 \pm 5$ & $4.2 \pm 2.7 \mathrm{~m}$ & $113 \pm 15$ & $45 \pm 8$ \\
\hline $\mathrm{HCM}$ & 12 & $3 / 9$ & $52 \pm 8$ & $8.3 \pm 4.2 \mathrm{~m}$ & $67 \pm 15$ & $74 \pm 7$ \\
\hline
\end{tabular}

\#Time from onset of subjective symptoms or clinical diagnosis to cardioscopy.

$n$, number of patients; $F$, female; M, male; LVG, left ventriculography; EDVI, left ventricular endodiastolic volume index; $\mathrm{EF}$, ejection fraction; SA, stable angina; m, months; UA, unstable angina; d, days; AMI, acute myocardial infarction; $\mathrm{OMI}$, old myocardial infarction; AM, acute idiopathic myocarditis; CM, chronic idiopathic myocarditis; RVD, rheumatic valvular disease; DCM, idiopathic dilated cardiomyopathy; HCM, idiopathic hypertrophic cardiomyopathy.

\section{Methods}

\section{Subjects}

From 1 April 2001 to 31 March 2008, 258 patients with heart diseases [104 females and 154 males; mean age \pm SD, 63 \pm 6 years; 56 with stable angina (SA), 9 with unstable angina (UA), 42 with acute myocardial infarction (AMI), ${ }^{20} 43$ with old myocardial infarction (OMI; 1 month or more since the onset of AMI) complicated with or without SA, ${ }^{21} 21$ with $\mathrm{AM}$ and 38 with chronic myocarditis diagnosed based on Japanese Circulation Society criteria, ${ }^{22} 6$ with rheumatic valvular disease, 31 with idiopathic DCM and 12 with idiopathic hypertrophic cardiomyopathy] diagnosed by ventriculography and endomyocardial biopsy, ${ }^{23}$ underwent cardioscopy for detection of LVT (Table 1).

The present study was performed at Toho University Medical Center, Sakura Hospital and Funabashi-Futawa Hospital and was approved by their Institutional Review Boards. All the patients provided informed consent for the procedures.

\section{Non-Invasive Examinations Before Cardiac Catheterization}

On admission, chest X-rays, electrocardiograms, blood sampling, and transthoracic non-contrast UCG followed by contrast-UCG were carried out. Contrast-UCG was not performed in hemodynamically unstable patients, so they were excluded from the analyses.

\section{Cardioscopy System}

The cardioscopy system was composed of a light source, 4.5-F fiberscope, 9-F guiding balloon catheter, intensified chilled coupled device camera, camera controller, DVD recorder and television monitor.

The fiberscope (AF 14; Olympus Corporation, Tokyo) was composed of a 4.5-F fiberscope containing 3,000 glass fibers for image guidance and 300 glass fibers for light guidance. The fiberscope could be passed through the 9-F guiding balloon catheter (Clinical Supply Co, Gifu, Japan). The balloon was inflatable with $\mathrm{CO}_{2}$. The catheter had a Y connecter at the proximal end; 1 channel for fiberscope insertion and another for saline solution flush. The fiberscope and guiding balloon catheter have been approved for clinical use by the Japanese Ministry of Health, Labor and Welfare.

\section{Observation of the LVT by Cardioscopy}

In a preliminary experimental cardioscopic study, it was confirmed that the thrombi that had formed on the endocardial surface of the infarcted portion were not detached by saline solution infusion using a power injector toward the thrombi. ${ }^{16}$

At first, the right femoral artery was cannulated and left ventriculography and coronary angiography were performed. Cardioscopy was performed in the patients based on this result. In brief, after left ventriculography, a guiding balloon catheter was introduced into the left ventricle so its distal tip was in a location that did not touch the endocardium, usually in the middle portion of the ventricle, and the balloon was inflated with $\mathrm{CO}_{2}$ to make a dead space between the fiberscope and the target. Next, a fiberscope was introduced into the guiding catheter to place the fiberscope tip at the distal most end of the guiding catheter. Thereafter, the guiding balloon catheter was slowly advanced while infusing heparinized $(10 \mathrm{U} / \mathrm{ml})$ saline solution at a rate of $5-10 \mathrm{ml} / \mathrm{s}$ for $5 \mathrm{~s}$ to displace the blood between the target and the fiberscope. When a thrombus was detected, the catheter was stopped so it did not touch the thrombus. The anterior, apical, lateral and inferior wall segments of the left ventricle were surveyed in each patient. When a thrombus was detected in a segment, the other segments were not surveyed. The guiding balloon catheter tip was pre-shaped into a " $\mathrm{S}$ "-configuration for observation of the anterior, apical and inferior wall segments, and in a " $\mathrm{J}$ "-configuration for the lateral wall segment observation. ${ }^{18}$

Cardioscopic measurement of thrombus size was difficult because the images obtained by cardioscopy were fish-eye images. ${ }^{18}$

Cardioscopic images were displayed on a television monitor simultaneously with the fluoroscopic images and electrocardiogram. The details of the cardioscopic procedures are reported elsewhere and are shown in Figure 1.17-19

\section{Classification of LVT}

The LVT were classified by their configuration into globular (a large thrombus protruding into the cardiac chamber occupying the entire visual field of a cardioscope) and mural (a small sized thrombus attached to the left ventricular luminal surface, not protruded, and not occupying the entire visual field of the cardioscope).

The color of the thrombi was classified into red, cotton 

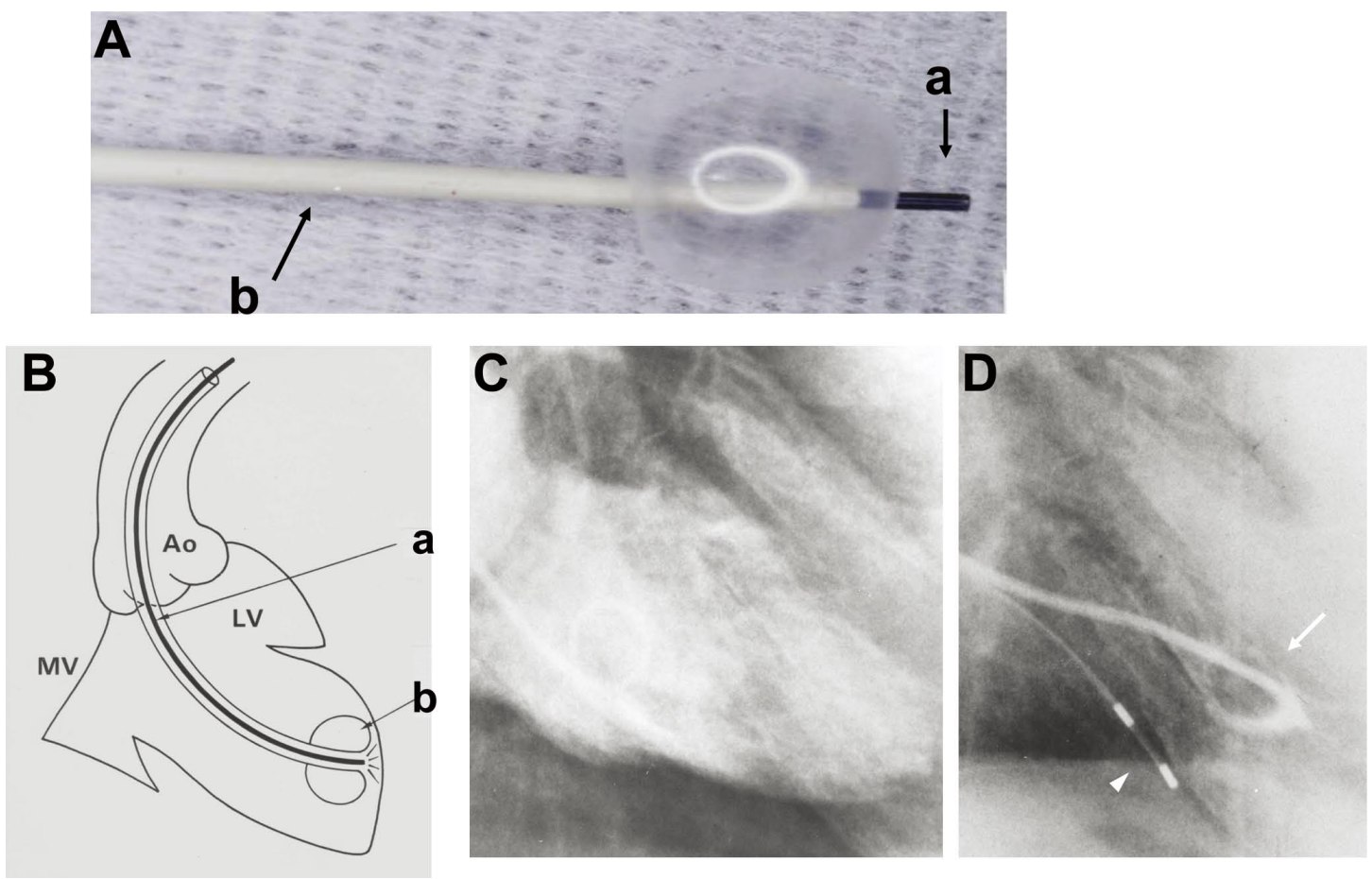

Figure 1. Cardioscope and its manipulation. (A) Lateral view of a cardioscope that is composed of a fiberscope (a) and a guiding balloon catheter (b). (B) Schematic representation of the manipulation. The balloon (b) of the guiding balloon catheter was gently pushed against the endocardial surface to create a dead space. Saline solution was injected into the dead space to displace the blood, and the endocardial surface was observed by the fiberscope (a). (C) Left ventriculogram at diastole. (D) Injection of a contrast material to determine the location of the angioscope tip (arrow). Arrowhead, a pacemaker electrode.
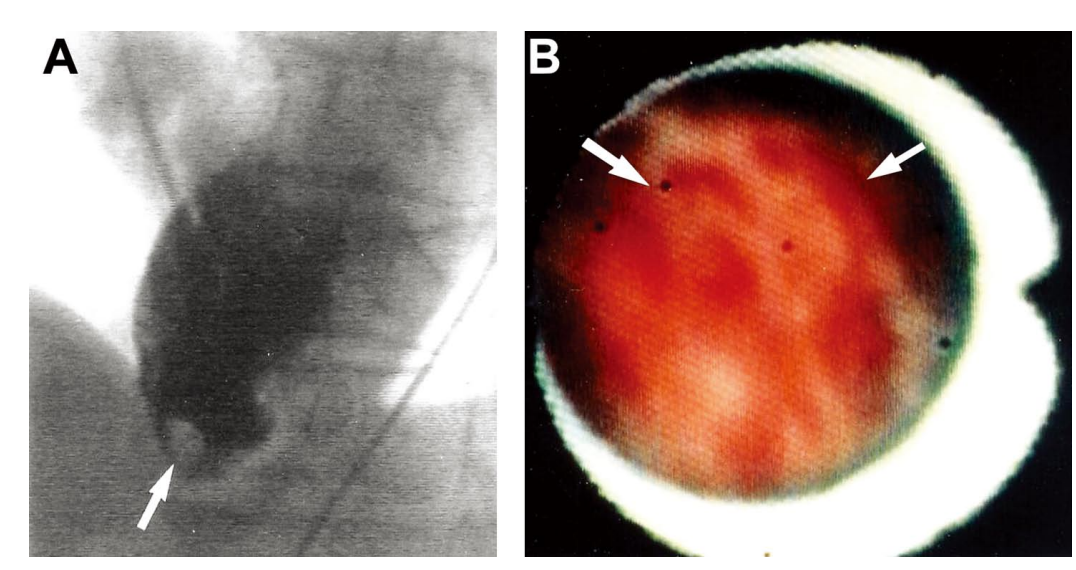

Figure 2. A globular left ventricular thrombus (LVT). A 57-year-old male with old myocardial infarction (40 days after the onset of acute myocardial infarction). (A) Left ventriculogram at left anterior oblique projection. A globular defect in the akinetic apical segment, suggesting a thrombus (arrow). (B) Cardioscopic image. A globular LVT with a red-and-white in a mosaic pattern (arrow) that corresponded to the defect in $(\mathbf{A})$.

candy-like white, red-and-white in a mosaic pattern, yellow, and red-and-yellow in a mosaic pattern. Intraobserver and interobserver agreements on red, cotton candy-like white, redand-white in a mosaic pattern, yellow, and red-and-yellow in a mosaic pattern LVT were $96 \%, 88 \%, 81 \%, 100 \%$, and $100 \%$, respectively, and $91 \%, 88 \%, 81 \%, 97 \%$, and $100 \%$, respectively.

\section{Statistical Analysis}

The data obtained were tested by Fischer's exact test. A $\mathrm{P}<0.05$ was considered significant.

\section{Results}

\section{Representative Examples}

Figure 2 shows a globular thrombus that was red-and-white in a mosaic pattern and was attached to the luminal surface of the infarcted apical wall segment of the left ventricle in a patient with OMI.

Figure 3 shows demonstrable examples of mural LVT with different colors, namely red, white, yellow, and redand-yellow in a mosaic pattern. 


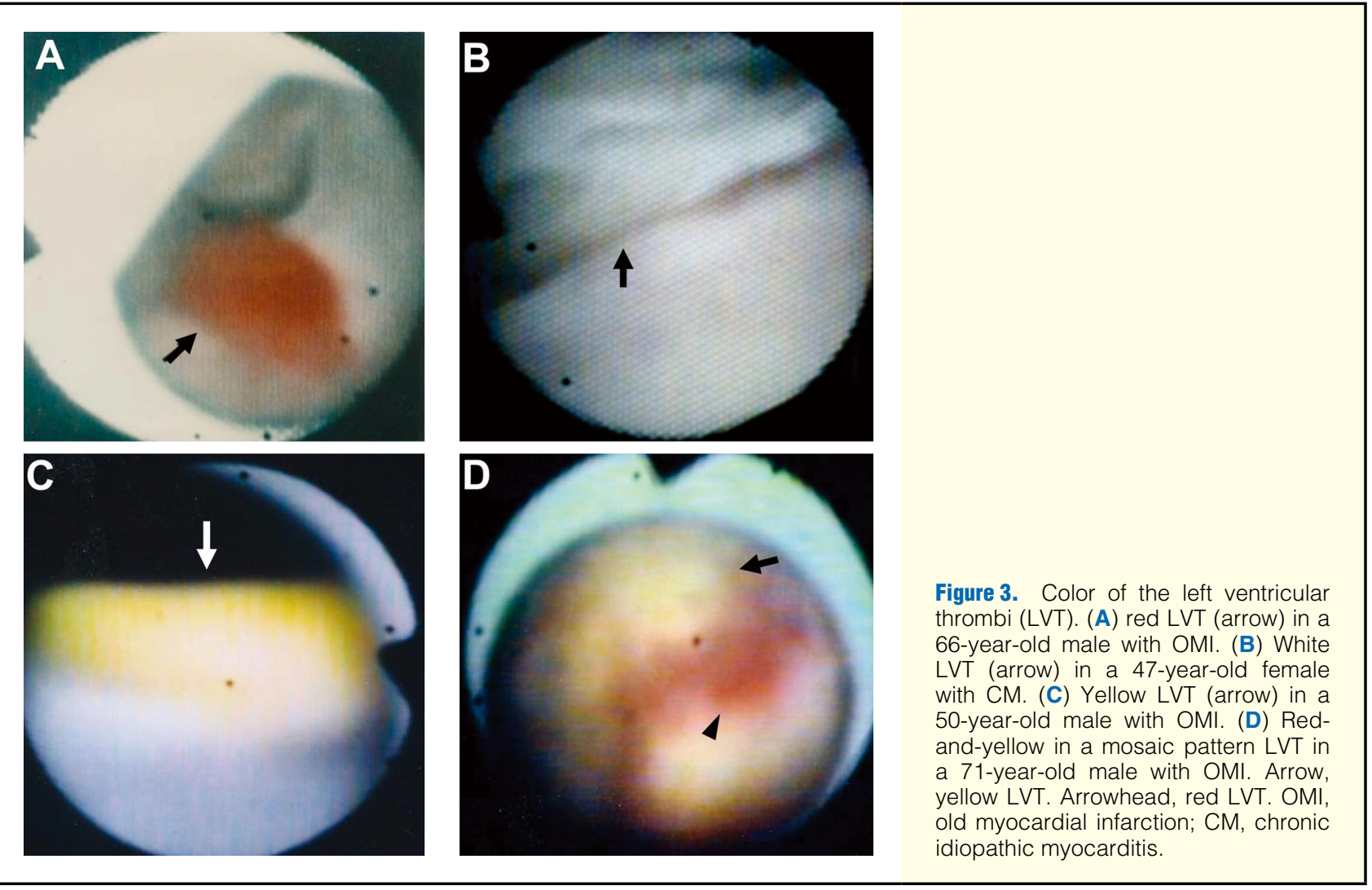

\begin{tabular}{|c|c|c|c|c|c|c|}
\hline \multirow[b]{2}{*}{ Heart diseases } & \multirow[b]{2}{*}{$\mathbf{n}$} & \multicolumn{2}{|c|}{ Cardioscopy } & \multirow[b]{2}{*}{ LVG } & \multicolumn{2}{|c|}{ UCG } \\
\hline & & $\begin{array}{l}\text { Thrombus } \\
\text { present (\%) }\end{array}$ & $\begin{array}{l}\text { Thrombus } \\
\text { globular/mural }\end{array}$ & & Non-cont & Cont \\
\hline SA & 56 & $7(12.5)$ & $0 / 7$ & 0 & 0 & 0 \\
\hline UA & 9 & $0(0.0)$ & $0 / 0$ & 0 & 0 & 0 \\
\hline AMI & 42 & $20(45.2)^{\star *}$ & $5 / 15$ & 4 & $5\left(2^{\#}\right)$ & $6(1 \#)$ \\
\hline $\mathrm{OMI}$ & 43 & $10(23.2)$ & $2 / 8$ & 2 & 2 & 4 \\
\hline$A M$ & 21 & $13(61.9)^{\dagger}$ & $2 / 11$ & 2 & $3\left(1^{\#}\right)$ & 5 \\
\hline $\mathrm{CM}$ & 38 & $17(44.3)$ & $0 / 17$ & 0 & 0 & 3 \\
\hline RVD & 6 & 2 (33.3) & $0 / 2$ & 0 & 0 & 0 \\
\hline DCM & 31 & $8(25.7)$ & $0 / 8$ & 0 & 0 & 0 \\
\hline $\mathrm{HCM}$ & 12 & $1(8.0)$ & $0 / 1$ & 0 & 0 & 0 \\
\hline Total & 258 & $78(30.2)^{\ddagger \ddagger}$ & $9 / 69$ & $8(2.7)$ & $10(1.9)$ & $18(7.0)$ \\
\hline
\end{tabular}

LVT, left ventricular thrombi; UCG, echocardiography; Non-cont, non-contrast UCG; Cont, contrast UCG. Other abbreviations are as per Table 1.

${ }^{*} \mathrm{P}<0.01$ vs. $S A .+\mathrm{P}<0.05$ vs. CM. $\neq \mathrm{P}<0.0001$ vs. LVG Non-cont and Cont. \#Thrombus suspected but inconclusive.

\section{Incidence of LVT by Cardioscopy}

The incidence of LVT in AMI was 45.2\%, which was higher than in the SA group, but was not different to that of the OMI group. The incidence of LVT in the AM group was $61.9 \%$ and it was higher than that of the CM group. Although lower in incidence, LVT were observed in all other categories of heart disease except UA (Table 2).

\section{Morphology and Color of LVT}

Globular and mural thrombi were detected in 9 and 69 patients, respectively. Globular thrombi were observed in patients with AMI, OMI and AM. All globular LVT were located in the apical portion. LVT were mural in the other types of heart diseases (Table 2). The relationship between regional wall motion and presence or absence of LVT was not examined because left ventriculograms were obtained only in 2 directions and therefore to quantitatively measure regional wall motion at the site of LVT was difficult.

Red, cotton candy-like white, red-and-white in a mosaic pattern, yellow, and red-and-yellow in a mosaic pattern LVT were observed in $24,8,11,27$ and 2 patients, respectively. The incidence of red thrombi was higher than cotton candylike white and red-and-white in a mosaic pattern LVT. The incidence of yellow thrombi was higher $(\mathrm{P}<0.05)$ than cot- 


\begin{tabular}{|cccccc|}
\hline $\begin{array}{c}\text { Table 3. Color of LVT } \\
\begin{array}{c}\text { Heart } \\
\text { diseases }\end{array}\end{array}$ & Red & White & $\begin{array}{c}\text { Red-and- } \\
\text { white }\end{array}$ & Yellow & $\begin{array}{c}\text { Red-and- } \\
\text { yellow }\end{array}$ \\
SA & 0 & 1 & 1 & 5 & 0 \\
UA & 0 & 0 & 0 & 0 & 0 \\
AMI & 11 & 3 & 6 & 0 & 0 \\
OMI & 2 & 1 & 1 & 6 & 0 \\
AM & $8^{\star}$ & 3 & 2 & 0 & 0 \\
CM & 2 & 0 & 1 & $12^{\dagger \dagger}$ & 2 \\
RVD & 1 & 0 & 0 & 1 & 0 \\
DCM & 3 & 0 & 2 & 3 & 0 \\
HCM & 0 & 1 & 0 & 0 & 0 \\
Total & $24^{\ddagger}$ & 8 & 11 & $27 \S$ & 2 \\
\hline
\end{tabular}

Abbreviations as per Tables 1,2.

${ }^{*} \mathrm{P}<0.05$ vs. $\mathrm{CM}$. ${ }^{+t} \mathrm{P}<0.01$ vs. AM. $\neq \mathrm{P}<0.05$ vs. White, Red-andwhite and Red-and-yellow. ${ }^{\circledR} \mathrm{P}<0.05$ vs. White, Red-and-white, and Red-and-yellow.

ton candy-like white and red-and-white in a mosaic pattern LVT. Yellow LVT was more frequently observed in CM than in AM (Table 3).

\section{Comparison of Sensitivity in Detecting LVT Among Cardioscopy, Non-Contrast UCG and Contrast UCG}

LVT was detected by cardioscopy, left ventriculography, non-contrast UCG and contrast-UCG in $30.2 \%, 2.7 \%, 1.9 \%$, and $7.0 \%$, respectively, of the patients. The detection rate for cardioscopy was higher $(\mathrm{P}<0.0001)$ than that for the other 3 imaging modalities. Although globular LVT were detected, mural LVT were only slightly detectable by left ventriculography, non-contrast UCG and contrast UCG (Table 2). The detection rate of contrast UCG was higher $(\mathrm{P}<0.01)$ than that of non-contrast UCG (Table 2).

\section{Complications}

No serious complications such as cerebral or systemic embolism were noted during or after cardioscopy.

\section{Treatments}

Anticoagulant therapy with warfarin was performed in patients with globular thrombus until the thrombus had disappeared on contrast UCG. Antiplatelet therapy with aspirin and/or ticlopidine was performed in all patients with AMI and OMI to prevent coronary thrombosis, irrespective of the presence or absence of LVT. These treatments were not carried out in patients with other types of heart disease having mural LVT.

\section{Follow up for 1 Year}

Twenty-one days after cardioscopy, cerebral ischemic attack occurred despite the use of warfarin in a patient with OMI in whom a globular thrombus was observed. A 1-year followup study was completed with 189 patients. In addition to the above mentioned patient, cerebral ischemic attacks were observed in 3 patients with mural thrombus and in 1 patient without mural thrombus. Atrial fibrillation was not observed in any of these patients. Whether the thrombi observed by cardioscopy were the sources of cerebral ischemic attacks was not determined.

\section{Discussion}

\section{Incidence of LVT}

In the present study, LVT were observed by cardioscopy, on average, in approximately $30 \%$ of patients with heart diseases, suggesting that LVT was prevalent in patients with heart diseases.

LVT was observed in AMI and AM more frequently than in other heart diseases. It is known that LVT are formed more frequently in a left ventricle with contraction disturbance or deformation, which causes stagnation and turbulence of blood flow. The left ventricular contraction (ejection fraction) was reduced in patients with AMI and AM. This might be the reason why LVT was frequent in these 2 diseases. Although left ventricular contraction was also decreased in patients with DCM, the incidence of LVT was less than that in AMI and AM. Loss of antiplatelet and/or anticoagulant activity of the endocardial cells due to ischemia or inflammation might have also contributed to the higher incidence of LVT in AMI and AM. Occurrence of LVT in patients with SA might have also been due to ischemia-induced endocardial cell damages. ${ }^{18}$

Fibrillating atrium is a major supplying source of thromboemboli in patients with ischemic cerebral attacks. In the present follow-up study, ischemic cerebral attacks occurred in 4 patients without atrial fibrillation. Although definite evidence is lacking, there is a possibility that LVT was the mother thrombus.

\section{Determination of Composition and Age of LVT by Color}

It is well known that a thrombus (in any vessel or cardiac chamber) formed exhibits a red color within a few days; a dark-red color at around 1 week; and a yellow color due to deposition of $\beta$-carotene and organization around 1 month. When red blood cells are washed out from the surface of a recently formed thrombus, the thrombus appears soft and exhibits a white color due to exposed platelets and fibrin. ${ }^{24}$ Therefore, the red, cotton candy-like white, red-and-white in a mosaic pattern, yellow, and red-and-yellow in a mosaic pattern LVT were considered to be fresh, fresh, fresh, old, and fresh-and-old in mixture, respectively, and, red, white and cotton-candy-like white, red-and-white in a mosaic pattern were considered to be red blood-rich, fibrin and/or plateletrich, and both red blood cell- and fibrin and/or platelet-rich, respectively.

LVT exhibiting red, cotton candy-like white, red-and-white in a mosaic pattern, and red-and-yellow in a mosaic pattern were observed in chronic diseases, suggesting repeated formation of fresh thrombi even in chronic diseases. In addition to the anatomical and functional properties of the left ventricle, the loss of anti-thrombotic action of the endocardial cells and changes in humoral mechanisms such as the thrombotic, thrombolytic and fibrinolytic actions of the blood might have contributed to the repeated LVT formation.

\section{Comparison With Other Imaging Modalities}

The rate of detection of LVT by cardioscopy was significantly higher than that by non-contrast and contrast UCG in the present study, indicating that cardioscopy is a more sensitive method for detecting LVT.

Siebenlink observed LVT by contrast UCG in $9.0 \%$ (conclusive) of 156 patients with post-infarction. ${ }^{5}$ Weinsaft observed LVT by non-contrast UCG in $6 \%$ and by contrast UCG in $12 \%$ of 121 patients with post-infarction. ${ }^{12}$ In the present study, the patients with myocardial infarction were observed by non-contrast UCG in $5.8 \%$ and by contrast UCG 
in $11.6 \%$. The detection rate by non-contrast and contrast UCG were not different among these 3 studies.

Weinsaft observed LVT by delayed-enhanced magnetic resonance in $16.3 \%$ of 121 patients with myocardial infarction. ${ }^{12}$ LVT were observed in $35.1 \%$ of 85 patients with myocardial infarction in the present study. Although a comparison was not performed in the same patient population, the sensitivity of cardioscopy for detecting LVT seems higher $(\mathrm{P}<0.05)$ than that of magnetic resonance imaging.

Magnetic resonance imaging can survey the entire left ventricle whereas cardioscopic observation is limited to at most 4-5 sections due to the limited volume of saline solution useable for blood displacement. Which of these 2 imaging modalities is more sensitive at detecting LVT remains to be elucidated.

Magnetic resonance imaging shows only the shadow of the thrombus, whereas cardioscopy can observe the thrombus directly. Therefore, it is evident that the specificity of cardioscopy is superior to that of magnetic resonance imaging and any other clinically available imaging modality with respect to detecting $\mathrm{LVT}$.

\section{Source of Cerebral Embolism}

In addition to the left atrium, the carotid arterial trees, ${ }^{25}$ subclavian artery, ${ }^{26}$ aortic arch, ${ }^{27}$ ascending and descending aortae, ${ }^{28}$ and venous thrombi through a patent foramen ovale ${ }^{29}$ are not infrequently the source of emboli in cerebral ischemic stroke. However, the source of the emboli is not routinely determined in $25-50 \%$ of patients. ${ }^{30}$

The left ventricle has not received attention as a source of emboli supply. The results from the present study strongly suggest that the left ventricle is an important source of emboli in cerebral ischemic attacks.

\section{Complications and Clinical Usefulness of Cardioscopy}

If it is demonstrated that cerebral ischemic attacks occur in patients with small-sized mural LVT, cardioscopy, although invasive, can be used for detection of the LVT because they are only slightly detectable by other imaging modalities. This technique is easy for clinicians who are skillful at cardiac catheterization. However, it is essential that the LVT not be touched by the tip of the guiding catheter or fiberscope in order to avoid LVT detachment and the resultant embolism.

\section{Study Limitations}

Cardioscopic observation of the left ventricular endocardial surface was limited up to 4 wall segments due to the limited volume (up to $500 \mathrm{ml}$ to prevent the occurrence of acute congestive heart failure) of the saline solution necessary for displacement of the blood. It was therefore unclear whether thombi existed in other segments.

\section{Conclusions}

LVT were detected by percutaneous cardioscopy in 78 of 258 patients with various types of heart disease. The incidence of LVT was higher in patients with AMI and AM than in other categories of heart diseases. The LVT were globular in 9 and mural in 69. The overall detection rate was $30.2 \%$, $2.7 \%, 1.9 \%$, and $7.0 \%$ by cardioscopy, ventriculography, non-contrast UCG and contrast UCG, respectively, indicating that cardioscopy is more sensitive than the other 3 imaging modalities for detecting LVT.

\section{Disclosures}

There are no conflicts of interest to disclose. Relationships With Industry: No relationships. Funds: This study was performed without financial support.

\section{References}

1. Becker RC. Thrombogenesis in atrial fibrillation contributing mechanisms and natural history. J Thromb Thrombolysis 2009; 27: 119121.

2. Han SW, Nam HS, Kim SH, Lee KY, Heo JH. Frequency and significance of cardiac sources of embolism in TOAST classification. Cerebrovasc Dis 2007; 24: 463-468.

3. Kaviak ES, Kucukoglu H, Yigit Z, Okcun B, Baran T, Ozkan AA, et al. Clinical and echocardiographic risk factors for embolization in the presence of left atrial thrombus. Echocardiography 2007; 24: $515-521$.

4. Bemhardt P, Schmidt H, Hammerstingl C, Luedenitz B, Omran H. Atrial thrombi-a prospective follow-up study over 3 years with transesophageal echocardiography and cranial magnetic resonance imaging. Echocardiography 2006; 23: 388-394.

5. Siebelink HM, Scholte AJ, Van de Veire NR, Holman ER, Nucifora $\mathrm{G}$, van der Wall EE, et al. Value of contrast echocardiography for left ventricular thrombus detection post-infarcton and impact on antithrombotic therapy. Coron Artery Dis 2009; 20: 462-466.

6. Kane A, Mbaye M, Ndiaye MB, Diuao M, Moreira PM, Mboup C, et al. Evolution and thromboembolic complications of the idiopathic peripartal cardiomyopathy at Dakar University Hospital: Forwardlooking study about 33 cases. J Gynecol Obstet Biol Reprod 2010; 39: $484-489$ (in French).

7. Choi SH, Jeong SI, Yang JH, Kang IS, Jun TG, Lee HJ, et al. A single-center experience with intracardiac thrombosis in children with dilated cardiomyopathy. Pediatr Cardiol 2010; 31: 264-269.

8. Aboukhoudir F, Rekik S, Hirsch JL. Images in cardiovascular medicine: Live echocardiographic visualization of the migration of a voluminous left ventricular thrombus complicating an acute myocarditis. Circulation 2009; 120: e8-e10.

9. Sen T, Gungor O, Akpinar I, Cetin M, Tufekcioglu O, Goldbasi Z. Cardiac involvement in hypereosinophilic syndrome. Tex Heart Inst J 2009; 36: 628-629.

10. Buchibinder NA, Yu R, Rosenbloom BE, Sherman CT, Silberman AW. Left ventricular thrombus and embolic stroke caused by a functional paraganglioma. J Clin Hypertens 2009; 11: 734-737.

11. Cianciulli TF, Saccheri MC, Lax JA, Neme RO, Sevillano JF, Maiori ME, et al. Left ventricular thrombus mimicking primary cardiac tumor in a patient with primary antiphospholipid syndrome and recurrent systemic embolism. Cardiol J 2006; 16: 560-563.

12. Weinsaft JW, Kim RJ, Ross M, Krauser D, Manoushagian S, LaBounty TM, et al. Contrast-enhanced anatomic imaging as compared to contrast-enhanced tissue characterization for detection of left ventricular thrombus. JACC Imaging 2009; 2: 969-979.

13. Tehrani F, Eshanghian S. Detection of left ventricular thrombus by computed tomography angiography. Am J Med Sci 2009; 338: 167168.

14. Yamashita E, Takamatsu H, Tada H, Toide H, Okaniwa H, Takamura N. Transesophageal echocardiography for thrombus screening prior to left atrial catheter ablation. Circ J 2010; 74: 1080-1086.

15. Sakuam M, Nakamura M, Yamada N, Ota S, Shirato K, Nakano T, et al. Venous thromboembolism: Deep vein thrombosis with pulmonary embolism, deep vein theombosis alone, and pulmonary embolism alone. Circ J 2009; 73: 305-309.

16. Uchida Y, Nakamura F, Tomaru T, Sonoki H, Sugimoto T. Fiberoptic observation of cardiac chambers, valves and great vessels using a guiding balloon catheter in dogs. Am Heat J 1988; 118: $1297-1302$.

17. Uchida Y, Nakamura F, Ohshima T. Percutaneous fiberoptic angioscopy of the left ventricle in patients with dilated cardiomyopathy and acute myocarditis. Am Heart J 1990; 120: 677-687.

18. Uchida Y. Atlas of Cardioangioscopy. Tokyo: Medical View Co, 1995; $93-161$.

19. Uchida Y. Percutaneous fiberoptic angioscopy of cardiac chambers and valves. In: Zipes DP, Rowlands BJ, editors. Progress in Cardiology. Philadelphia: Lea \& Febiger, 1991; 163-191.

20. Antman EM, Braunwald E. ST-elevation myocardial infarction: Pathophysiology and clinical features. In: Zipes DP, Libby P, Bonow RO, Braunwald E, editors. Heart Disease, $7^{\text {th }}$ Edition. Philadelphia: Elsevier Saunders, 2005; 1141-1165.

21. Morrow DA, Gersch BJ, Braunwald E. ST-elevation myocardial infarction. In: Zipes DP, Libby P, Bonow RO, Braunwald E, editors. 
Heart Disease, $7^{\text {th }}$ Edition. Philadelphia: Elsevier Saunders, 2005; $1281-1354$.

22. Japanese Circulation Society Task Force Committee. Guidelines for diagnosis and treatment of acute and chronic myocarditis. 2009; 68(Suppl IV): $1-40$.

23. Wynne J, Braunwald E. The cardiomyopathies. In: Zipes DP, Libby P, Bonow RO, Braunwald E, editors. Heart Disease, $7^{\text {th }}$ Edition. Philadelphia: Elsevier Saunders, 2005; 1659-1696.

24. Uchida Y. Percutaneous pulmonary angioscopy using a balloon guiding catheters in dogs. Clin Cardiol 1988; 11: 143-148.

25. Christian BA, Kirzender DL, Boyd J, Laing J, Gash JR. Showered calcific emboli to the brain, the 'salted pretzel' sign, originating from the ipsilateral internal carotid artery causing acute cerebral infarction. Stroke 2009; 40: e319-e321.

26. Gooneratne IK, Gamage R, Gunarathne KS. Pearls \& oysters: Distalsubclavian artery: A source of cerebral embolism. Neurology
2009; 73: e11-e12.

27. Faggioli G, Ferii M, Rapezzi C, Tonon C, Manzoli L, Stella A. Atherosclerotic aortic lesions increase the risk of cerebral embolism during carotid stenting in patients with complex aortic arch anatomy. J Vasc Surg 2009; 49: 80-85.

28. Harioff A, Simon J, Brandecks S, Assefa D, Helbing T, Frydrychowicz A, et al. M. Complex plaques in the proximal descending aorta: An underestimated embolic source of stroke. Stroke 2010; 41: $1145-1150$.

29. Jauss M, Wessels T, Trittmacher S, Allendoerfer J, Kaps M. Embolic lesion pattern in stroke patients with patients lacking an embolic source. Stroke 2006; 37: 2159-2161.

30. Duebrava J, Garay R. The role of transesophageal echocardiography in detection of cardiogenic and aortic sources of embolism in stroke and transient ischemic attacks. Vnitr Lek 2006; 52: 144-151. 